Document downloaded from:

http://hdl.handle.net/10251/167319

This paper must be cited as:

Colangelo, F.; Gómez-Navarro, T.; Farina, I.; Petrillo, A. (2020). Comparative LCA of concrete with recycled aggregates: a circular economy mindset in Europe. International Journal of Life Cycle Assessment. 25(9):1790-1804. https://doi.org/10.1007/s11367-02001798-6



The final publication is available at

https://doi.org/10.1007/s11367-020-01798-6

Copyright Springer-Verlag

Additional Information 
LCA OF WASTE MANAGEMENT SYSTEMS

\title{
Comparative LCA of concrete with recycled aggregates: a circular economy mindset in Europe
}

\author{
Francesco Colangelo ${ }^{1} \&$ Tomás Gómez-Navarro ${ }^{2}$ \& llenia Farina ${ }^{1}$ \& Antonella Petrillo ${ }^{1}$
}

\begin{abstract}
Construction and demolition waste (C\&DW) is the largest waste stream in the European Union (EU) and all over the world. Proper management of $\mathrm{C} \& \mathrm{DW}$ and recycled materials-including the correct handling of hazardous waste—can have major benefits in terms of sustainability and the quality of life. The Waste Framework Directive 2008/98/EC aims to have $70 \%$ of C\&DW recycled by 2020 . However, except for a few EU countries, only about $50 \%$ of C\&DW is currently being recycled. In the present research, the environmental impact of concrete with recycled aggregates and with geopolymer mixtures is analysed. The aim of the present research is to propose a comparative LCA of concrete with recycled aggregates in the context of European politics.

Life cycle assessment (LCA) methodology is applied using Simapro@ software. A cradle to grave analysis is carried out. The results are analysed based on the database Ecoinvent 3.3 and Impact 2002+.

Results show that the concrete with $25 \%$ recycled aggregates is the best solution from an environmental point of view. Furthermore, geopolymer mixtures could be a valid alternative to reduce the phenomenon of "global warming"; however, the production of sodium silicate and sodium hydroxide has a great environmental impact.

A possible future implementation of the present study is certainly to carry out an overall assessment and to determine the most cost-effective option among the different competing alternatives through the life cycle cost analysis.
\end{abstract}

Keywords C\&DW $\cdot$ LCA $\cdot$ Recycled aggregate $\cdot$ Circular economy $\cdot$ Geopolymer concrete mixtures

\section{Introduction}

Construction and demolition waste (C\&DW) are the heaviest and most voluminous waste streams generated in the EU and all over the world. C\&DW waste generation around the world

Responsible editor: Holger Wallbaum

$*$ Antonella Petrillo

antonella.petrillo@uniparthenope.it

Francesco Colangelo

francesco.colangelo@uniparthenope.it

Tomás Gómez-Navarro

tgomez@dpi.upv.es

Ilenia Farina

ilenia.farina@uniparthenope.it

1 Department of Engineering, University of Naples "Parthenope", Isola C4, Centro Direzionale Napoli, 80143 Naples, NA, Italy

2 Departamento deProyectos de Ingeniería, Universitat Politècnica de València, Camino de vera s/n., 46022 Valencia, Spain reached approximately 3 billion tonnes (Akhtar and Sarmah 2018). While, in Europe, it accounts for approximately 25$30 \%$ of all waste generated and consists of numerous materials, including concrete, bricks, gypsum, wood, glass, metals, plastic, solvents, asbestos and excavated soil, many of which can be recycled (Provis 2017; Davidovits 2018; Walling et al. 2019; Gluth et al. 2017). Thus, C\&DW has been identified as a priority waste stream by the European Union (Tangtinthai et al. 2019; Mercante et al. 2012). There is a high potential for recycling and re-use of C\&DW, since some of its components have a high resource value. In particular, there is a re-use market for aggregates derived from C\&DW waste in roads, drainage and other construction projects (Gálvez-Martos et al. 2018; Colangelo and Cioffi 2017). That is why the European Commission introduced a new protocol (EU Construction and Demolition Waste Protocol and Guidelines 2016) on construction and demolition. This protocol fits within the Construction 2020 strategy (COM (2012) 433), as well as the Communication on Resource Efficiency Opportunities in the Building Sector (COM (2014) 445). It is also part of the 
European Commission's ambitious and more recently adopted Circular Economy Package. The proposed actions will contribute to reaching the Waste Framework Directive (2008/98/EC) target of $70 \%$ of C\&D waste being recycled by 2020 , closing the loop of product lifecycles through greater recycling and re-use and bringing benefits for both the environment and the economy. And more is currently done at local, regional, national and EU levels (Di Maria et al. 2018). One of the objectives of the Waste Framework Directive (2008/98/EC) is to provide a framework for moving towards a European recycling society with a high level of resource efficiency. The scope of the Protocol includes waste from construction, renovation and demolition works. However, one of the common hurdles to recycling and reusing Construction and Demolition waste in the EU is the lack of confidence in the quality of $\mathrm{C} \& \mathrm{D}$ recycled materials. Furthermore, the European Commission has issued the Communications "A resource efficient Europe" and "Roadmap to a Resource Efficient Europe", the stated goal of which is to reconsider the whole life cycle of resource use so as to make the European Union a "circular economy", one based on recycling and the use of waste as a resource. Moreover, life cycle assessment (LCA) and life cycle thinking (LCT) is core to many of these policies (Blengini et al. 2017; Colangelo et al. 2018b). In this context, C\&DW is a possible source of unconventional aggregates, which are recognised as essential and valuable resources for the economic and social development of modern societies (Blengini et al. 2012). In Italy, we are very far from the target $(70 \%)$ imposed by the Directive (2008/98/EC), especially in the regions of southern Italy due to the presence of many legal and illegal mines and the access to natural aggregates that is very cheap (Pantini et al. 2019). Thus, upon the above considerations, the motivation behind this work can be summarized as follows:

(i) ensure the reduction of the volume of aggregates in landfill;

(ii) re-use of rubble after earthquakes; (iii) decrease of excavations for the production of aggregates; (iv) implement sustainable practices in the construction industry in order to have a win-win situation that is mutually beneficial to the environment, society, and the economy.

In detail, the present research evaluates the environmental impacts associated with the non-hazardous C\&DW management by applying the LCA methodology (from cradle to grave). In fact, according to the European Union policies, life cycle assessment (LCA) is a widespread tool to assess the environmental benefits and burdens associated to waste management systems and to identify strategies that will improve their performance (ISO 14040 2006; ISO 14044 2006).

In the present research, eight different types of concrete have been analysed, i.e. with recycled aggregates, natural aggregates and Portland cement (PC)-based concretes versus alkali-activated ground granulated blast furnace slag (GGBFS)-based concretes. The research is limited to alkaline-activated GGBFS. GGBFS-based concrete are considered as third-generation cement after lime and ordinary Portland cement. On average, they have good mechanical strength, low permeability, good chemical resistance, and excellent fire resistance (Petrillo et al. 2016). It is relevant to note that PC-based concretes and the wide variety of alkali-activated/geopolymer concretes can be diametrically opposed to each other in respect to their technical properties (consistency, working time, strength development, resistance to environmentalimpact, occupational safety aspects), and theirenvironmental impact cannot be considered isolated from these aspects. Thus, the final aim of the present study is to outline possible research prospects to be followed in the near future according to the European Union regulation. One main novelty of the present research paper is to consider the impacts deriving from the production of the steel necessary for concrete reinforcement. Furthermore, interesting considerations can be drawn about examined GGBFS mixtures. In the literature, it is very difficult to find such mixtures with recycled aggregates having a compressive strength of $30 \mathrm{MPa}$, as in our case study. In order to summarize the research lines following a state of art of the topic under study is analysed, materials and methods are described, and the main contributions of the research and future developments are explained.

\section{State of art on life cycle approach of C\&DW}

The increasing volume of C\&DW associated with economic growth is posing challenges to the sustainable management in the construction sector (Zhang et al. 2019). In this regard, significant efforts have been devoted to assessing C\&DW management. The need for broad-scope empirical measurement of the environmental performance of C\&DW management system has been emphasised in scientific studies and common political discussion (Lu and Yan 2011). However, in our opinion, there is little knowledge to understand the proper utilisation of the developed models for assessing C\&DW environmental impacts (Wu et al. 2019). Our aim was to investigate the use of LCA methodology applied to C\&DW management. The SCOPUS database was used, since it is the world's largest abstract and citation database of peerreviewed research literature. The literature review pointed out some interesting studies that adopt LCA methodology to assess C\&DW performance. Obviously, the literature analysis below is not intended to be exhaustive but aims to highlight only research that is most in line with our scientific interest. Thus, after careful analysis, some scientific papers have been selected and are described in detail below. The results of the main scientific papers analysed, and in line with our research, are summarised in Tables 1 and 2. More in detail, Table 1 summarizes the main information about the analysed studies. 
Table 1 Literature related to LCA and C\&DW-functional unit, system boundaries, materials and methods

\begin{tabular}{|c|c|c|c|c|c|}
\hline \multirow[t]{2}{*}{ Authors } & \multirow[t]{2}{*}{ Functional unit } & \multicolumn{4}{|c|}{ Materials and methods } \\
\hline & & $\begin{array}{l}\text { Fixed and mobile } \\
\text { recycling plant }\end{array}$ & $\begin{array}{l}\text { Recycled } \\
\text { aggregates }\end{array}$ & $\begin{array}{l}\text { Natural } \\
\text { aggregates }\end{array}$ & $\begin{array}{l}\text { System } \\
\text { boundaries }\end{array}$ \\
\hline $\begin{array}{l}\text { Blengini et al. } \\
\text { (2010) }\end{array}$ & $\begin{array}{l}1 \mathrm{t} \text { of collected and } \\
\text { recycled C\&DW }\end{array}$ & $\mathrm{X}$ & $X$ & & $\begin{array}{l}\text { Cradle to } \\
\text { grave }\end{array}$ \\
\hline $\begin{array}{l}\text { Borghi et al. } \\
\quad(2018)\end{array}$ & $\begin{array}{l}1 \mathrm{t} \text { of non-hazardous } \\
\text { C\&DW }\end{array}$ & $\mathrm{X}$ & $\mathrm{X}$ & & $\begin{array}{l}\text { Cradle to } \\
\text { grave }\end{array}$ \\
\hline $\begin{array}{l}\text { Estanqueiro } \\
\text { et al. (2018) }\end{array}$ & $1 \mathrm{t}$ of coarse aggregates & $\mathrm{X}$ & & $\mathrm{X}$ & $\begin{array}{l}\text { Cradle to } \\
\text { gate }\end{array}$ \\
\hline $\begin{array}{l}\text { Vossberg } \\
\text { et al. (2014) }\end{array}$ & $\begin{array}{l}1 \mathrm{t} \text { of collected and } \\
\text { recycled aggregates }\end{array}$ & $\mathrm{X}$ & & & $\begin{array}{l}\text { Cradle to } \\
\text { grave }\end{array}$ \\
\hline $\begin{array}{l}\text { Marinković } \\
\text { et al. (2010) }\end{array}$ & $1 \mathrm{~m}^{3}$ of concrete & - & $\mathrm{X}$ & $\mathrm{X}$ & $\begin{array}{l}\text { Cradle to } \\
\text { gate }\end{array}$ \\
\hline $\begin{array}{l}\text { Tošić et al. } \\
\text { (2015) }\end{array}$ & $1 \mathrm{~m}^{3}$ of concrete & - & $\mathrm{X}$ & & $\begin{array}{l}\text { Cradle to } \\
\text { gate }\end{array}$ \\
\hline $\begin{array}{l}\text { Colangelo } \\
\text { et al. (2018) }\end{array}$ & $1 \mathrm{~m}^{3}$ of concrete & - & $\mathrm{X}$ & & $\begin{array}{l}\text { Cradle to } \\
\text { gate }\end{array}$ \\
\hline $\begin{array}{l}\text { Braga et al. } \\
\quad(2017)\end{array}$ & $1 \mathrm{~m}^{3}$ of concrete & - & & $\mathrm{X}$ & $\begin{array}{l}\text { Cradle to } \\
\text { gate }\end{array}$ \\
\hline $\begin{array}{l}\text { Knoeri et al. } \\
\qquad(2013)\end{array}$ & $1 \mathrm{~m}^{3}$ of concrete & - & $\mathrm{X}$ & & $\begin{array}{l}\text { Cradle to } \\
\text { gate }\end{array}$ \\
\hline
\end{tabular}

On the other hand, Table 2 summarizes the database and the impact method used to perform a LCA study.
According to the literature analysis, an interesting study is proposed by Blengini and Garbarino (2010). In their study, a
Table 2 Literature related to LCA and C\&DW—-database and impact analysis method

\begin{tabular}{|c|c|c|c|c|c|}
\hline \multirow[t]{2}{*}{ Authors } & \multirow[t]{2}{*}{ Database } & \multicolumn{4}{|c|}{ Impactanalysis method } \\
\hline & & $\begin{array}{l}\text { Impact } \\
2002+\end{array}$ & $\begin{array}{l}\text { Econdicator } \\
99\end{array}$ & CML & $\begin{array}{l}\text { IPCC } \\
2007\end{array}$ \\
\hline $\begin{array}{l}\text { Blengini } \\
\text { et al. } \\
\text { (2017) }\end{array}$ & $\begin{array}{l}\text { Literature and database of provincia di Torino, } \\
\text { interview with operators, distances retrieved } \\
\text { from a GIS model }\end{array}$ & $\mathrm{X}$ & $\mathrm{X}$ & & \\
\hline \multirow{2}{*}{$\begin{array}{l}\text { Borghi et al. } \\
\quad(2018)\end{array}$} & Primary data for recycling plants (visited) & $\mathrm{X}$ & & & \\
\hline & $\begin{array}{l}\text { Literature and Ecoinvent for recycling of steel } \\
\text { and landfilling of inert }\end{array}$ & & & & \\
\hline $\begin{array}{l}\text { Estanqueiro } \\
\text { et al. } \\
\text { (2018) }\end{array}$ & Site-specific primary data & & & $\mathrm{X}$ & \\
\hline $\begin{array}{l}\text { Vossberg } \\
\text { et al. } \\
\text { (2014) }\end{array}$ & Interviews, Ecoinvent database & & & & $\mathrm{X}$ \\
\hline $\begin{array}{l}\text { Marinković } \\
\text { et al. } \\
\text { (2010) }\end{array}$ & $\begin{array}{l}\text { Primary data from their previous work, GEMIS } \\
\text { database }\end{array}$ & & & $\mathrm{X}$ & \\
\hline $\begin{array}{l}\text { Tošićetal. } \\
\text { (2015) }\end{array}$ & Primary data and GEMIS database & & & $\mathrm{X}$ & \\
\hline $\begin{array}{l}\text { Colangelo } \\
\text { et al. } \\
(2018)\end{array}$ & $\begin{array}{l}\text { Literature, SimaPro database, LCI from Italian } \\
\text { Technical Economic Association of Concrete } \\
\text { (ATECAP), literature review }\end{array}$ & & $\mathrm{X}$ & & \\
\hline $\begin{array}{l}\text { Braga et al. } \\
\text { (2017) }\end{array}$ & Companies and literature & & & $\mathrm{X}$ & \\
\hline $\begin{array}{l}\text { Knoeri et al. } \\
\text { (2013) }\end{array}$ & Ecoinvent, literature (distances) & & $X$ & & \\
\hline
\end{tabular}


combined geographical information system (GIS) and life cycle assessment (LCA) model is developed using site-specific data and paying attention to land use, transportation and avoided landfill. A real case study in the Turin (Italy) is analysed. One of the most interesting studies from our point of view is proposed by Marinković et al. (2010). The main purpose of this work was to determine the potentials of recycled aggregate concrete for structural applications and to compare the environmental impact of the production of natural aggregate concrete (NAC) made entirely with river aggregates and recycled aggregate concrete (RAC) made with natural fine and recycled coarse aggregates. On the other hand, Knoeri et al. (2013) analysed the life cycle impacts of 12 recycled concrete $(\mathrm{RC})$ mixtures with two different cement types and compared it with corresponding conventional concretes (CCs) for three structural applications. Afterwards, in 2014, Vossberg et al. (2014) presented the results of LCA on the energy requirements and greenhouse gas (GHG) emission implications of recycling C\&D rubble and container glass in Cape Town, South Africa. Tošić etal. (2015), according to the LCA methodology, identified the optimal choice of aggregate type and transport scenario in concrete production, employing a multicriteria optimization method considering technical, economic and environmental limits and constraints. Recently, Braga et al. (2017) performed a life cycle assessment of concrete (cradle to gate) including all stages except application, maintenance and demolition stages. More recently, Borghi et al. (2018) applied the LCA methodology, in Lombardy Region (Italy), to evaluate the environmental performance of the current regional management of C\&DW and to identify critical aspects and possible improving actions. On the other side, Estanqueiro et al. (2018) analysed an interesting point of view. In fact, in their study, LCA was used to compare the environmental impacts of three alternatives of procurement of coarse aggregates for concrete production: extraction and processing of natural aggregates; in addition, recycling of demolished concrete either using a fixed or a mobile plant was analysed. Finally, Colangelo et al. (2018a) applied the standard protocol of life cycle assessment to 3 different concrete mixtures composed by wastes from construction and demolition (C\&D), marble sludge and cement kiln dust (CDK) in order to compare the environmental and energy impacts. The main purpose was to analyse the potentials (capabilities/benefits) of recycled aggregate concrete.

The literature analysis highlighted applications, concrete types, aggregates, cement amount and the functional unit considered in the other studies developed according to LCA methodology. An important issue concerns the choice of the functional unit. In the analysed papers, different types of functional units are chosen with respect to the specific study. The importance of literature analysis was twofold. First, it allowed us to have an overview how the topic is addressed in the scientific community.
Secondly, it allowed us to collect and analyse data useful for our research.

\section{Materials and methods}

LCA study (ISO 140402006 ), consists of four phases that are described in the following four subsections.

\subsection{Phase no.1-goal and scope}

A comparative LCA of concrete with recycled aggregates and $\mathrm{PC}$ versus GGBFS-based concrete mixtures is proposed.

\subsubsection{Functional unit}

In this work, the functional unit (FU) is represented by 1 cubic meter of reinforced concrete with a compressive strength of $30 \mathrm{MPa}$ to be used in a building. In this way, in addition to considering the use of raw materials needed for the production of the building material, the contribution of steel to the sustainability of a building is also highlighted.

\subsubsection{Functional flows}

Different types of concrete have been analysed with recycled aggregates and GGBFS-based concrete mixtures. In total, eight concrete mixtures were prepared using CEM-I Portland cement conforming to EN 197-1 with $R_{c k}$ 32.5 MPa and recycled and natural aggregates (with an amount of recycled aggregates ranging from 0 to $100 \%$ ) and using both a traditional binder and GGBFS as precursor of the alkaline-activated binder. All the mixtures displayed a good workability; the slump was measured through the Abrams cone method, and it resulted as S4 slump class, ranging between 19 and $20 \mathrm{~cm}$. The SimaPro $(C)$ software was used to follow the ISO 14040-44 standards. The four mixtures of concrete with recycled and natural aggregates are those suggested in the study by Etxeberria et al. (2007).

Table 3 Mix proportioning of concrete mixtures with Type I Portland cement (compressive strength $30 \mathrm{MPa}$ )

\begin{tabular}{lllll}
\hline & C0 & C25 & C50 & C100 \\
\hline Cement $\left(\mathrm{kg} / \mathrm{m}^{3}\right)$ & 300 & 300 & 318 & 325 \\
Water $\left(1 / \mathrm{m}^{3}\right)$ & 165 & 165 & 165 & 162 \\
Recycled aggregate $\left(\mathrm{kg} / \mathrm{m}^{3}\right)$ & 0 & 266 & 536 & 1123 \\
Sand $\left(\mathrm{kg} / \mathrm{m}^{3}\right)$ & 765 & 765 & 739 & 683 \\
Gravel $\left(\mathrm{kg} / \mathrm{m}^{3}\right)$ & 1207 & 905 & 609 & 0 \\
Density $\left(\mathrm{kg} / \mathrm{m}^{3}\right)$ & 2442 & 2408 & 2372 & 2301 \\
\hline
\end{tabular}


Table 3 shows the mix proportioning of the following four mixtures:

- Mixture with cement as binder and 0\% recycled aggregates (C0)

- Mixture with cement as binder and 25\% recycled aggregates (C25)

- Mixture with cement as binder and 50\% recycled aggregates (C50)

- Mixture with cement as binder and $100 \%$ recycled aggregates (C100)

Table 4 shows, instead, four mix proportioning of the GGBFS-based mixtures under examination, prepared in the laboratory of the University of Naples "Parthenope":

- $\quad$ Mixture with GGBFS-based binder and 0\% recycled aggregates (G0)

- Mixture with GGBFS-based binder and 25\% recycled aggregates (G25)

- Mixture with GGBFS-based binder and 50\% recycled aggregates (G50)

- Mixture with GGBFS-based binder and 100\% recycled aggregates (G100)

Regardless of the type of binder, as the percentage of recycled aggregates increases, it is necessary to increase the amount of cement in order to guarantee the same mechanical properties. Furthermore, in these mixtures, granulated ground blast furnace slag (GGBFS) has been employed as binder. The amount of steel constituting the reinforcement in both sets of mixtures was assumed to be $120 \mathrm{~kg} / \mathrm{m}^{3}$ of concrete.

\subsubsection{System boundaries}

The LCA followed a cradle-to-grave approach, i.e. the life cycle of the concrete mixture is taken into

Table 4 Composition of geopolymer mixtures (compressive strength $30 \mathrm{MPa})$

\begin{tabular}{lllll}
\hline & G0 & G25 & G50 & G100 \\
\hline GGBFS $\left(\mathrm{kg} / \mathrm{m}^{3}\right)$ & 350 & 350 & 360 & 385 \\
Sand $\left(\mathrm{kg} / \mathrm{m}^{3}\right)$ & 737 & 737 & 737 & 737 \\
Natural aggregate $\left(\mathrm{kg} / \mathrm{m}^{3}\right)$ & 1098 & 841 & 503 & 0 \\
Recycled aggregate $\left(\mathrm{kg} / \mathrm{m}^{3}\right)$ & 0 & 239 & 521 & 953 \\
$\mathrm{NaOH}$ solution $\left(\mathrm{kg} / \mathrm{m}^{3}\right)$ & 67.5 & 67.5 & 67.5 & 67.5 \\
$\mathrm{Na} 2 \mathrm{SiO} 3$ solution $\left(\mathrm{kg} / \mathrm{m}^{3}\right)$ & 141.3 & 141.3 & 141.3 & 141.3 \\
Density $\left(\mathrm{kg} / \mathrm{m}^{3}\right)$ & 2397 & 2381 & 2336 & 2291 \\
\hline
\end{tabular}

consideration starting from the extraction of raw materials up to the demolition, considering that our case study is about a building. C\&DW, after the selective demolition, travels by road to the recycling plant, where it is treated; the secondary raw materials, output of waste treatment plant, are then sent to the concrete mixing plant. The natural aggregates are transported from the quarries to the concrete mixing plant where concrete is produced and then sent to the construction site. The impacts related to the construction, use and maintenance phases of the FU in the building have not been considered. This hypothesis is supported by numerous studies in the literature, summarized in Tables 1 and 2, and it is assumed that the impacts are the same for all the mixtures analysed. The analysis of the life cycle sees the demolition of the building as the final point; the steel of the demolished structure is assumed as sent to the recycling process and substitute primary steel somewhere else. Besides, the steel of the demolished structure is recycled, and $15 \%$ of the inert materials are landfilled, following the hypothesis defined by Colangelo et al. (2018). Regarding the remaining $85 \%$ of inert material, the process to which it is subjected has not been specified; this following the idea that in about 50 years (EN 1992-1-1: 2004), when the building will be subjected to partial or total demolition, the techniques of recovery will be reasonably changed. Figure 1 schematizes the building construction process for reinforced PC-based concrete.

The distances considered are the following:

- $\quad 30 \mathrm{~km}$ travelled by C\&DW from the demolition site to the fixed recycling plant

- $20 \mathrm{~km}$ covered by recycled aggregates from the treatment plant to the concrete plant

- $\quad 30 \mathrm{~km}$ from the cement production plant to the concrete mixing plant

- $\quad 30 \mathrm{~km}$ from the sand and gravel quarries to the concrete mixing plant

- $\quad 40 \mathrm{~km}$ from the concrete plant to the construction site

- $300 \mathrm{~km}$ travelled by steel for the building's reinforcement. This is approximately the distance that separates the steelworks of Taranto from a hypothetical construction site in the province of Naples.

Figure 2 schematizes the building construction process for GGBFS-based concrete. It is evident that the activities are similar to those of mixtures with traditional binder except the block relating to the production of the binder. Construction and demolition waste, after selective demolition, travel by road to get to the recycling plant to be treated, while the secondary raw materials, leaving the waste treatment plant, are treated in the concrete mixing plant. The natural aggregates are transported from the 
Fig. 1 Flow diagram for building construction process for reinforced PC-based concrete



quarries to the concrete mixing plant. In the concrete mixing plant, concrete is produced and then sent to the construction site. The impacts relating to the construction, use and maintenance phase were not considered according to numerous researches published in the literature (see Tables 1 and 2). On the other hand, most of the published studies propose the analysis of the impacts up to the production of aggregates or up to the production of concrete (Chen et al. 2020; Jafary Nasab et al. 2020; Colangelo et al. 2020; Gomes et al. 2020; Khan et al. 2019).

The distances considered are the following:
- $\quad 30 \mathrm{~km}$ travelled by C\&DW from the demolition site to the fixed recycling plant

- $20 \mathrm{~km}$ covered by recycled aggregates from the treatment plant to the concrete plant

- $\quad 100 \mathrm{~km}$ is the distance between the chemical plants that produce the precursors of the alkaline activated binder and the concrete mixing plant

- $30 \mathrm{~km}$ between the sand and gravel quarries to the concrete mixing plant

- $\quad 40 \mathrm{~km}$ is the distance travelled by the concrete from the concrete plant to the construction site
Fig. 2 Flow diagram relating to the life cycle of the building with GGBFS-based concrete

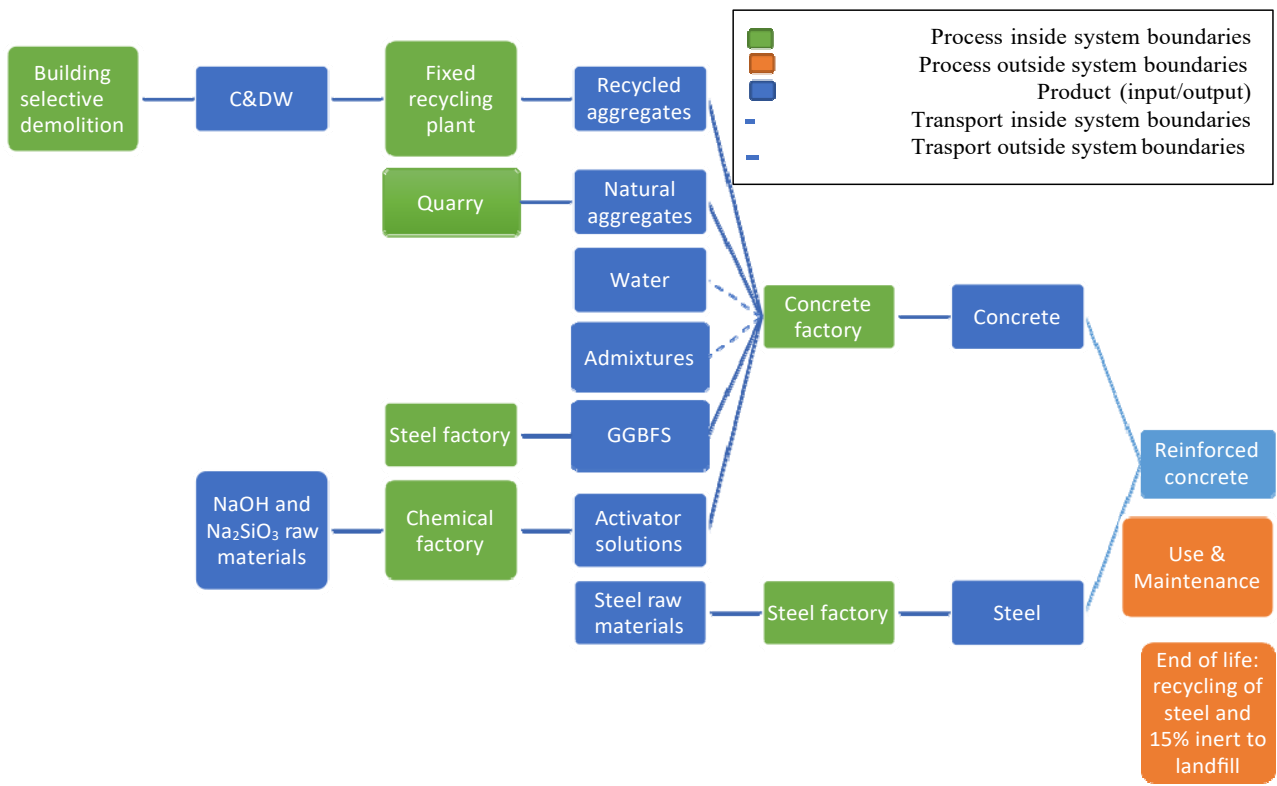


- $\quad 300 \mathrm{~km}$ is travelled by steel for the building's reinforcement and for the transport of the blast furnace slag from the steelworks to the concrete mixing plant

\subsection{Phase no. $2-\mathrm{LCl}$}

Data collection was based on the literature review, filed work or, alternatively, gathering information from the Ecoinvent 3 Life Cycle Inventory database.

In particular, the main assumptions are summarized as follows:

- For the gravel natural aggregate, the eco-profile is represented by the entry "Gravel, market for gravel, round RoW\}" in the Ecoinvent 3 database.

- For sand, fine natural aggregate, the entry "market for Sand $\{\mathrm{GLO}\}$ " from the Ecoinvent 3 database, constitutes its eco-profile.

- For recycled aggregates, the study by Borghi et al. (2018) has been considered. This study, supported by the administration of Lombardy region, has as its object the LCA of the current chain of disposal of demolition waste in Lombardy. Borghi et al. (2018) have quantified the consumption of electricity and fuel of fixed and mobile plants for the production of recycled aggregates. For the former, it has been estimated an electricity consumption of $1.74 \mathrm{kWh}$ per tonne of recycled aggregate produced; 0.381 of diesel is used to produce $1 \mathrm{t}$ of secondary raw material. Finally, $0.03 \mathrm{~kg}$ of steel is used in the production of $1 \mathrm{t}$ of recycled aggregate from a fixed plant.

- For the steel, the data present in Ecoinvent 3 were used under the entry "market for reinforcing steel $\{\mathrm{GLO}\}$ ".

- As regards cement, the eco-profile present in Ecoinvent 3 was used under the entry "market for cement, Portland \{Europe without Switzerland\}".

- For the transportation, it was assumed that the materials travel on road, so the impact connected to the transported tonnes $/ \mathrm{km}$ was assessed by referring to the item "Transport, freight, lorry 16-32 metric tonne, EURO5 $\{\mathrm{GLO}\} \mid$ market for $\mid$ Alloc Def, S" in the Ecoinvent 3 database. The data concerning the distances travelled will be discussed in the following sections.

- The data relating to additives were also obtained from the Ecoinvent 3 database. In particular, the item "Sodium hydroxide, without water, in $50 \%$ solution state $\{\mathrm{GLO}\}$ | market for | Alloc Def, S" has been chosen as representative of the inventory of sodium hydroxide in the geopolymer mixture.

- For the sodium silicate solution, it was chosen the entry Sodium silicate, without water, in $37 \%$ solution state $\{\mathrm{GLO}\} \mid$ market for $\mid$ Alloc Def, S; this represents the worst case from the point of view of the environmental loads, among the entries present in Ecoinvent regarding sodium silicate solutions. Data on the production of concrete in the concrete plant have been extrapolated from the study by Marinković et al. (2010), in which a life cycle analysis of a traditional concrete is drawn up. For the aforementioned study, $5575 \mathrm{kWh}$ of electricity is needed for the production of $1 \mathrm{~m}^{3}$ of ready-to-use concrete.

- Electric energy; the data present in Ecoinvent 3 have been used; in particular, it has been considered the medium voltage electricity produced in the Italian market.

- Also, data on the demolition of a building have been obtained from the study by Marinković et al. (2010). In particular, $89.59 \mathrm{MJ}$ of energy deriving from the combustion of diesel is needed to demolish $1 \mathrm{~m}^{3}$ of concrete.

- It is important to underline that when we talk about diesel consumption during demolition, we are using the entry "market for diesel, burned in agricultural machinery $\{\mathrm{GLO}\}$ " as a model of the inventory related to the combustion of the latter. This is because the aforementioned item is a good approximation of the impacts related to diesel subject to combustion in the engines of excavators and grinders (Marinković et al.2010).

- As regards the blast furnace slag, we are faced with an allocation problem, faced by several authors in the literature (Van den Heede and De Belie 2012; Sayagh et al. 2010; Chen et al. 2010; Van den Heede and De Belie 2012).

\subsection{Phase no. 3- LCIA}

Life cycle impact assessment (LCIA) is used to clarify the intensity of the LCI results with respect to their environmental effects. In this regard, it is relevant to note that although the endpoint effects are those we really care about, it can be difficult to measure them directly. Thus, most impact assessment methodologies use midpoint measurements. In this study, the life cycle impact assessment methodology IMPACT 2002+ was used since it suggests a feasible implementation of a combined midpoints/damage approach as suggested by several authors (Bare et al. 2000; Jolliet et al. 2003). These combinations link all types of life cycle inventory (LCI) results, the elementary flows and other interventions, throughout the 14 midpoint categories summed up to four damage categories. Normalization is carried out at midpoint level. The damage categories used by IMPACT 2002+ are:

Human Health, measured in DALY ("disability-adjusted life years") characterizes the disease severity, accounting for both mortality (years of life lost due to premature death) and morbidity (the time of life with lower quality due to an illness, e.g. at hospital). Default DALY values of 
13 and 1.3 (years/incidence) are adopted for most carcinogenic and non-carcinogenic effects, respectively

- Ecosystem quality, measured in $\mathrm{PDF}^{*} \mathrm{~m}^{2 *}$ year; ("Potentially disappeared fraction of species over a certain amount of $\mathrm{m}^{2}$ during a certain amount of year") is the unit to "measure" the impacts on ecosystems. The PDF. $\mathrm{m}^{2}$ year represents the fraction of species disappeared on $1 \mathrm{~m}^{2}$ of earth surface during 1 year. For example, a product having an ecosystem quality score of $0.2 \mathrm{PDF} \cdot \mathrm{m}^{2}$ year implies the loss of $20 \%$ of species on $1 \mathrm{~m}^{2}$ of earth surface during 1 year

Climate Change or "global warming", measured in kg of $\mathrm{CO}_{2}$ equivalent released to the air. The climate change damage factor of 9'950 kg CO2-eq/point is largely dominated by $\mathrm{CO} 2$ emissions

- Resources, expressed in MJ. Is the sum of the midpoint categories "non-renewable energy consumption" and "mineral extraction". The resources damage factor of $152,000 \mathrm{MJ} /$ point is largely dominated by nonrenewable energy consumption.

\subsection{Phase no. 4-interpretation}

The highest impacts occur in the production of cement, together with that of steel, which is however balanced by its recycling. In the case of geopolymer concrete, most of the impacts come from the production of sodium hydroxide and sodium silicate. The impacts related to steel are balanced by recycling operations. Figure $3 \mathrm{a}$ and $\mathrm{b}$ show the values of the impact indicators after the characterization phase. For each impact category, the most impacting mixture is shown with the value 100; the others in relation to the latter take values between 0 and 100 . With these first data, it is possible to understand which categories it is important to focus on in order to identify solutions that make concrete production more sustainable, as well as identify areas where there is a large inequality between one solution and another.

However, considering only the characterization phase, without comparing it with a reference point, would be too rough; the normalization phase therefore allows us to understand more clearly which categories are important to investigate. Figure 4 shows the analysis for: Global Warming, NonRenewable Energy, Respiratory Inorganics, Carcinogens, Non-Carcinoges and Terrestrial Ecotoxicity.

Geopolymers lead to a reduction of about $10 \%$ in global warming, although it is disadvantageous from the point of view of the other two categories.

Here below is a detail of the contribution of each category on the main individual processes in order to define the ecoprofile of eight mixtures.

\subsubsection{Global warming}

The results regarding $\mathrm{CO}_{2 \mathrm{eq}}$ emissions are shown in Fig. 5. Results highlight an advantage in adopting the technological solution represented by GGBFS binders. The sum of the impacts of the precursors is, in fact, always lower than the $\mathrm{CO}_{2 e q}$ released for cement production. The greater impact of transport is due to the longer distances that characterize the GGBFS-based concrete supply chain. Recycled aggregates are less impactful than natural ones. The GGBFS binder has an impact of $30 \%$ less than the traditional one without considering GGBFS ( $20 \%$ considering them). Steel accounts for about $13 \%$ of the total, not considering the recycling process. The mixtures with recycled aggregates and geopolymers represent the opportunity to further reduce the amount of $\mathrm{CO}_{2}$ emitted. This is because the amount of steel constituting the reinforcement can be reduced in the lighter mixtures while ensuring the same mechanical performance in response to earthquakes.

\subsubsection{Non-renewable energy}

From the point of view of the consumption of non-renewable energy resources (Fig. 6), the impacts associated with the production of sodium hydroxide and sodium silicate are the main obstacle to the competitiveness of the GGBFS binder. The use of recycled aggregates reduces the consumption of nonrenewable energy. GGBFS-based concretes have an impact of about $35 \%$ more than traditional concretes. Recycled aggregates have an impact of $75 \%$ less than natural aggregates, although they both are almost negligible compared with the other life cycle processes. Steel accounts for about $15 \%$ of the total mixture, not considering the recycling process.

\subsubsection{Respiratory inorganics}

In this impact category, it is still possible to underline the incidence of sodium silicate and sodium hydroxide (Fig. 7). Recycled aggregates have an impact equal to 0.3 times that of natural aggregates, also being very small. GGBFS-based concretes are more impactful because of silicate and sodium hydroxide. The relative contribution of steel to the Respiratory Inorganics category is about $3 \%$ in the cement concrete mixtures.

It is possible to notice how the use of GGBFS-based concrete involves a reduction of about $10 \%$ of global warming, although it is disadvantageous from the point of view of the other two categories highlighted. The use of recycled aggregates does not involve disadvantages; therefore, reducing the volume of inert waste in landfills, together with alleviating the pressure over the natural aggregate quarries, can only benefit the community. This result is in line with what was found in the literature 
Fig. 3 a Characterization and comparison among 8 mixtures using IMPACT 2002+. b

Characterization and comparison among 8 mixtures using IMPACT $2002+$



(a) Characterization, comparison among 8 mixtures using IMPACT 2002+

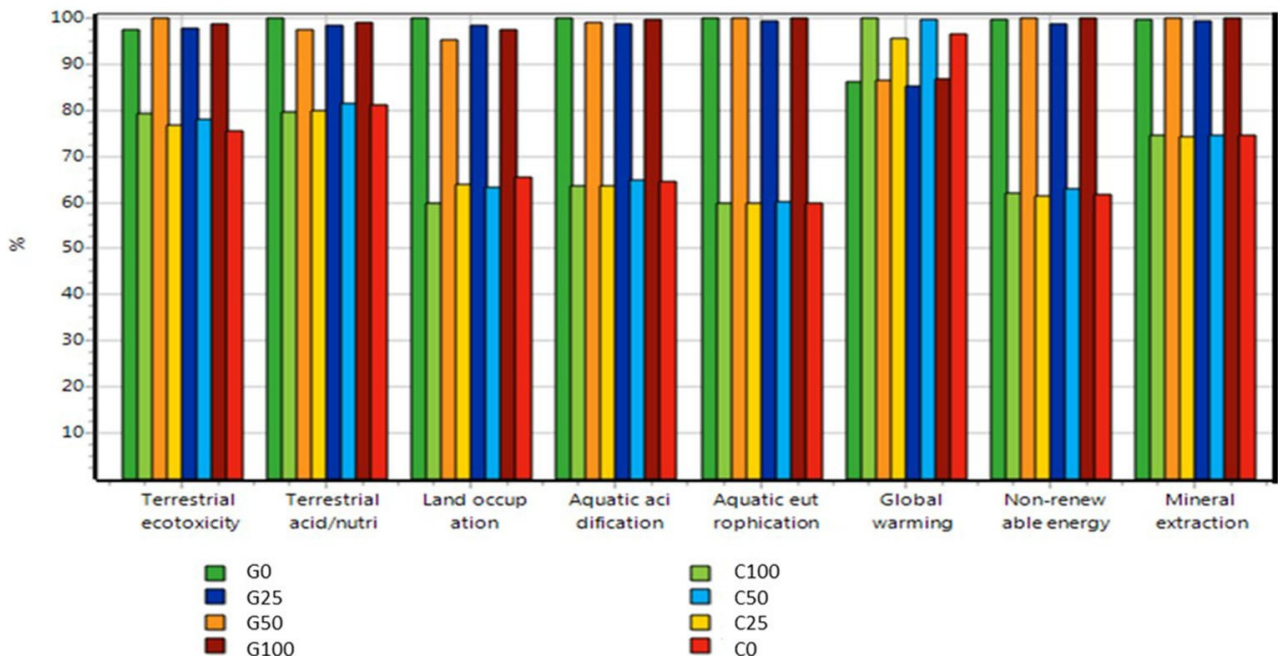

(b) Characterization, comparison among 8 mixtures using IMPACT 2002+

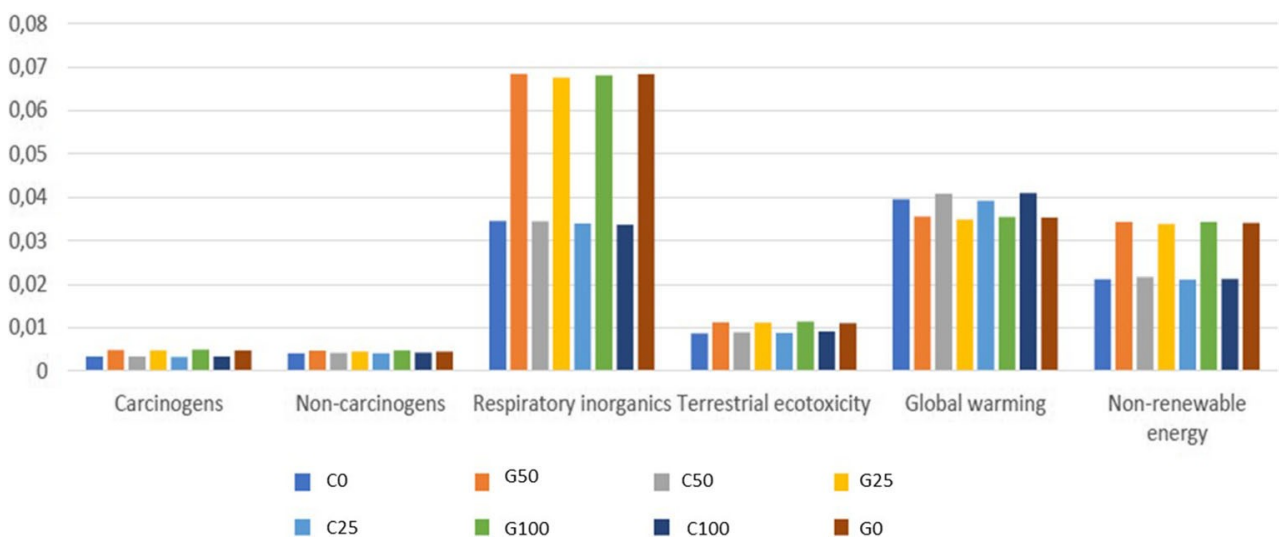

Fig. 4 Normalization and comparison between the 8 mixtures using the IMPACT $2002+$ method 
Global warming $\left(\mathrm{kg} \mathrm{CO} \mathrm{CO}_{2 \mathrm{eq}}\right)$

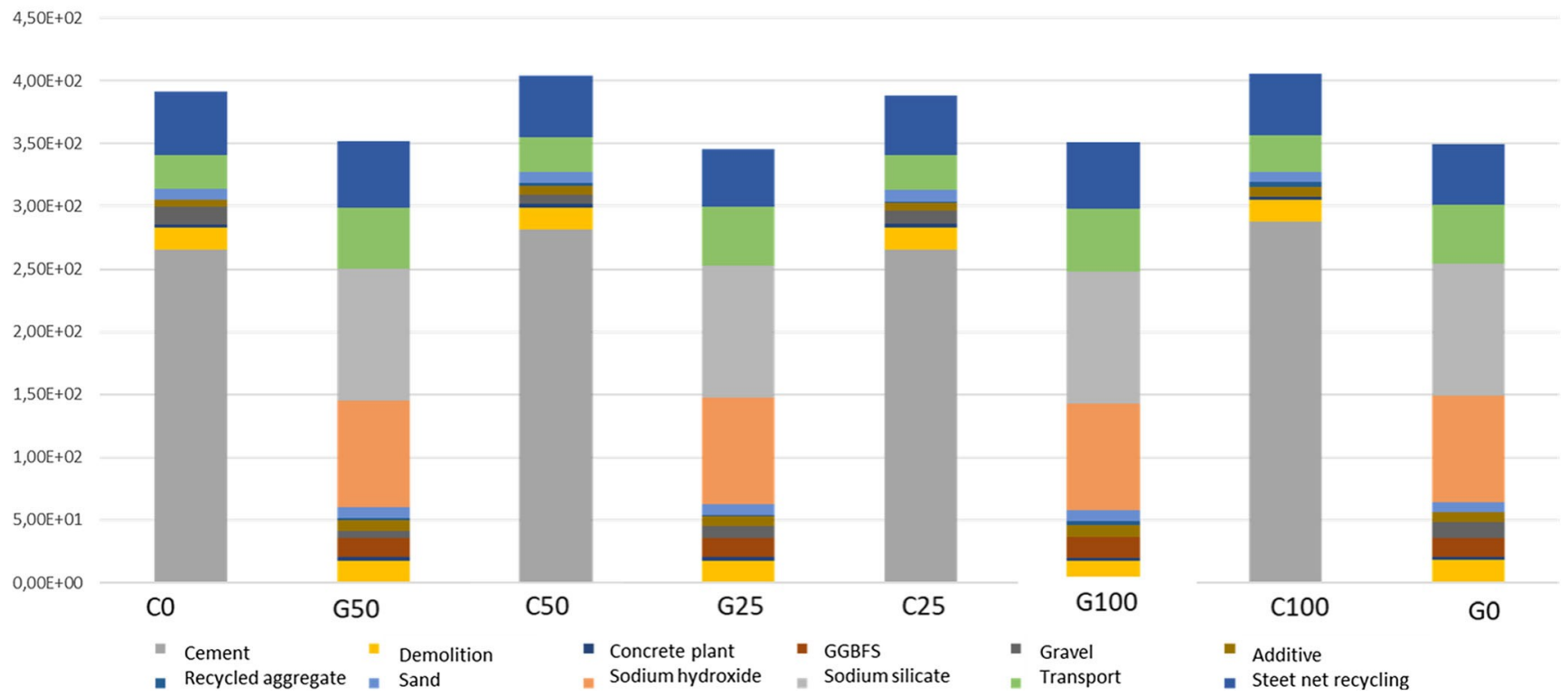

Fig. 5 Impact 2002+, normalization stage for each mixture, global warming impact category

(Marinković et al. 2010; Knoeri et al. 2013). As for GGBFS-based concrete, also in this case, the conclusions that can be drawn from the present work are in line with what can be found in the literature: the main advantage that can be derived from their use is the decrease of the greenhouse effect. In the other categories, however, their use is disadvantageous. While the $\mathrm{CO}_{2}$ released during the production of clinker is responsible for the greater greenhouse effect associated with the use of Portland cement; on the other hand, the energy needed to produce the precursors of GGBFS based concrete is the responsible of the impacts that are not negligible in the other categories. The search

Non-renewable energy (MJ primary)

$6,00 \mathrm{E}+03$

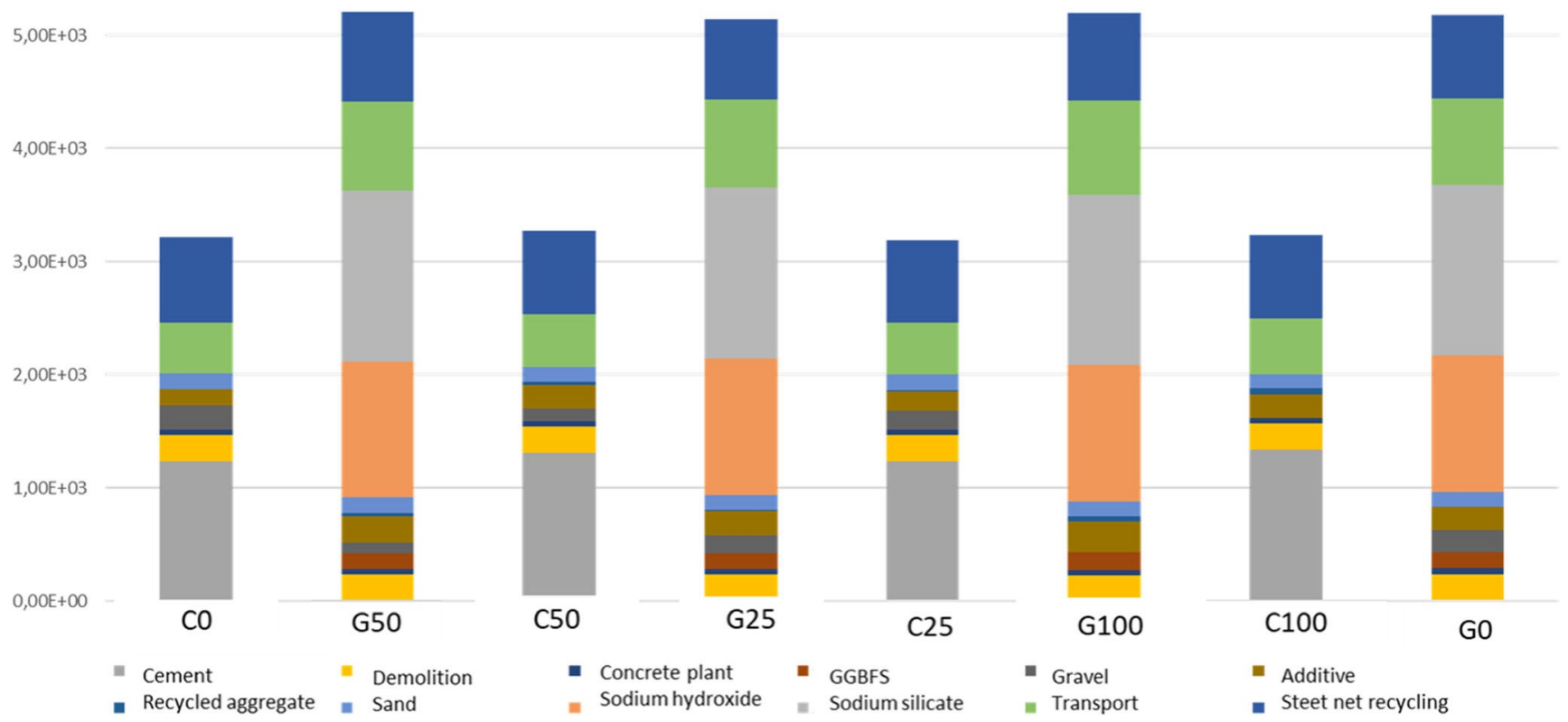

Fig. 6 Impact 2002+, normalization stage for each process, non-renewable energy 
$8,00 \mathrm{E}-01$

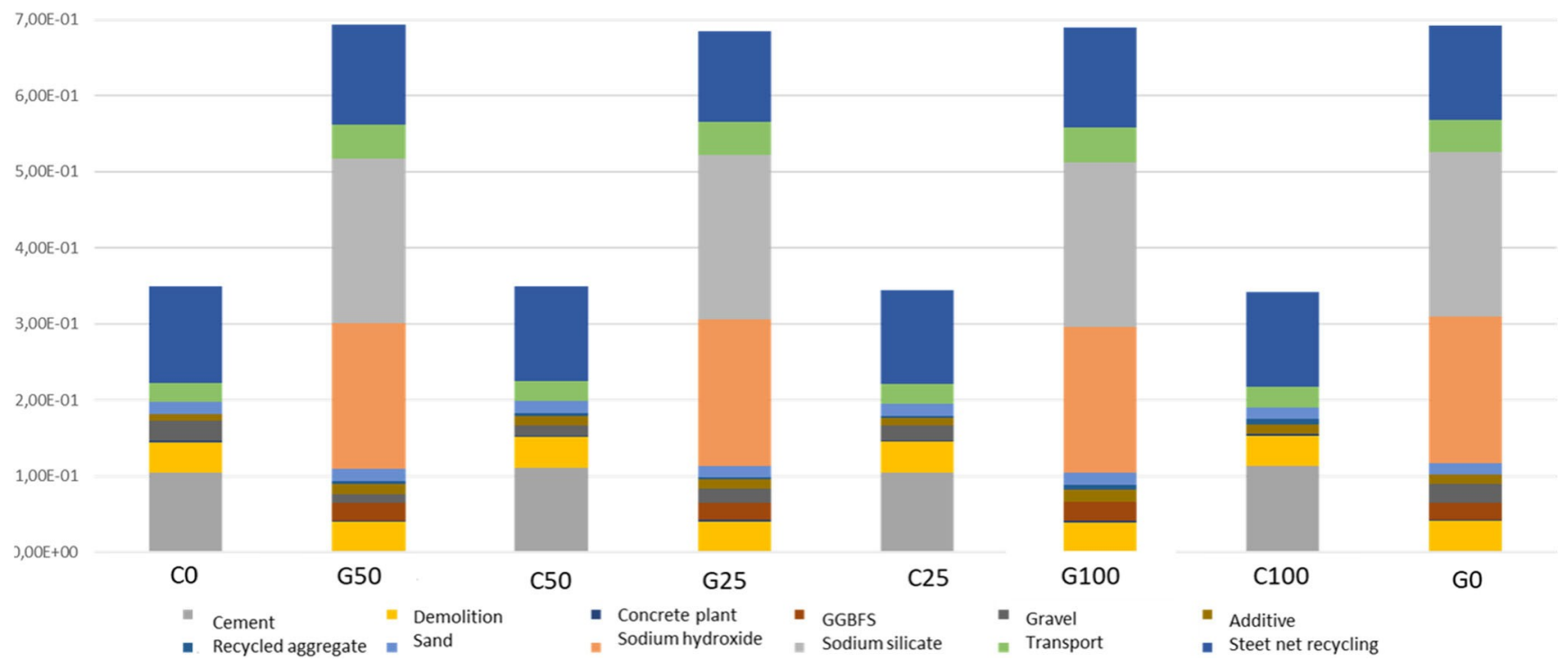

Fig. 7 Impact 2002+, normalization stage for process, respiratory inorganics

for alternative technologies for the production of the GGBFS-based concretes, as well as a replacement of the precursors, could be the solution to make them more competitive. The present study, therefore, is going to increase the number of researches in the sector, significantly contributing for having considered, within the life cycle, also the phases related to the production, transportation and recycling of steel.

\subsubsection{Carcinogens}

Figure 8 indicates a preference for traditional concrete. It is interesting to underline the strong dependence between this category of impact and the steel content in the mixtures, in a similar way to what happens for eutrophication. By reducing the amount of steel making up the reinforcement, it would be possible to reduce

Carcinogens $\left(\mathrm{kg} \mathrm{C}_{2} \mathrm{H}_{3} \mathrm{Cl}_{\mathrm{eq}}\right.$ )

$1,40 E+01$

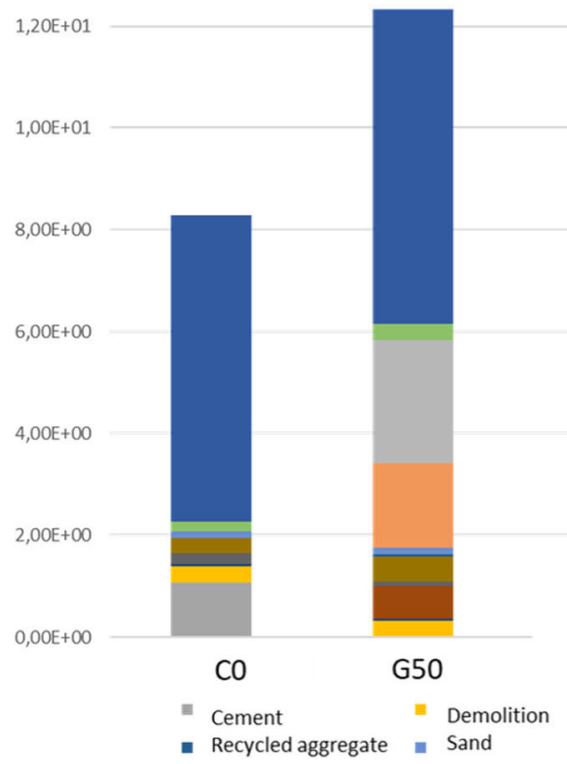

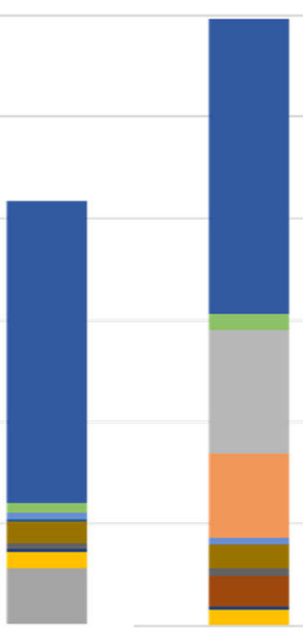

C50

- Concrete plant - Sodium hydroxide
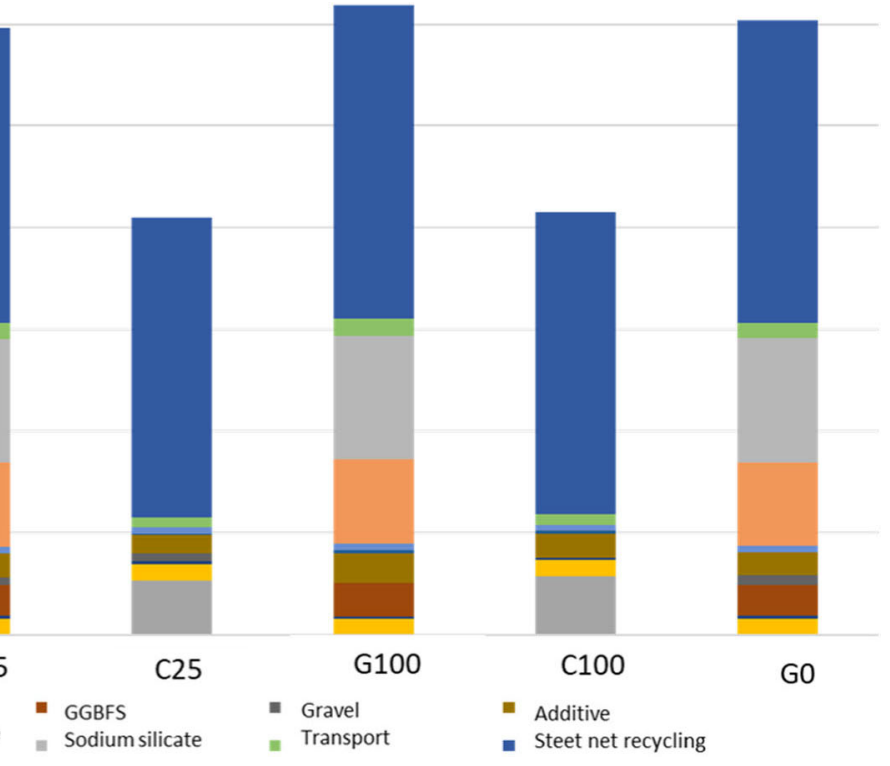

Fig. 8 Impact 2002+, normalization stage for each process, carcinogens 


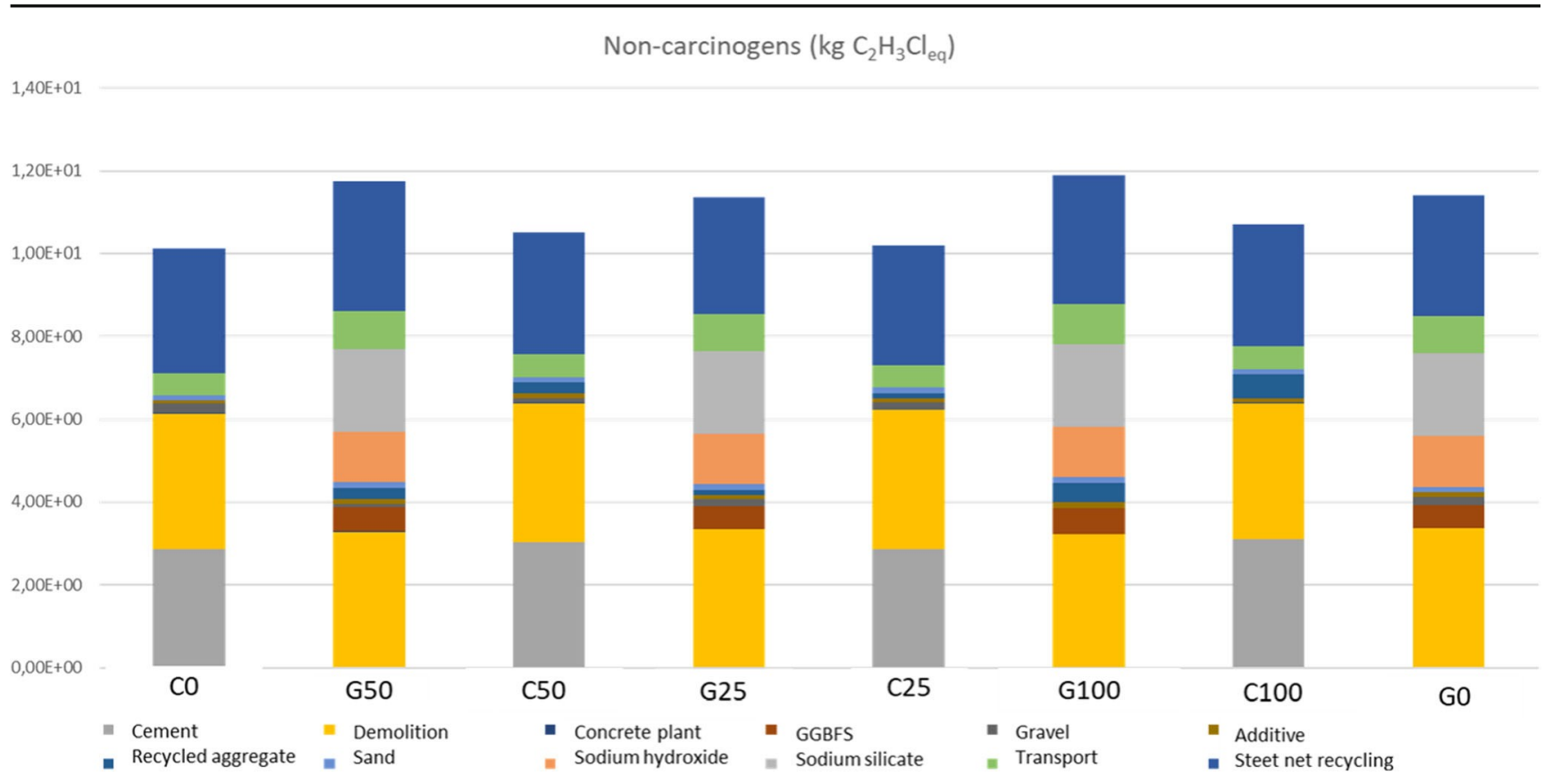

Fig. 9 Impact 2002+, normalization stage for each process, non-carcinogens

this impact considerably. The lower density of concrete with recycled aggregates could therefore push towards the adoption of mixtures with higher percentages of recycled aggregates.

\subsubsection{Non-carcinogens}

In this category, the impacts are strongly dependent on the steel and the binder. There is not a big difference between

\section{Terrestrial ecotoxicity (kg TEG soil)}

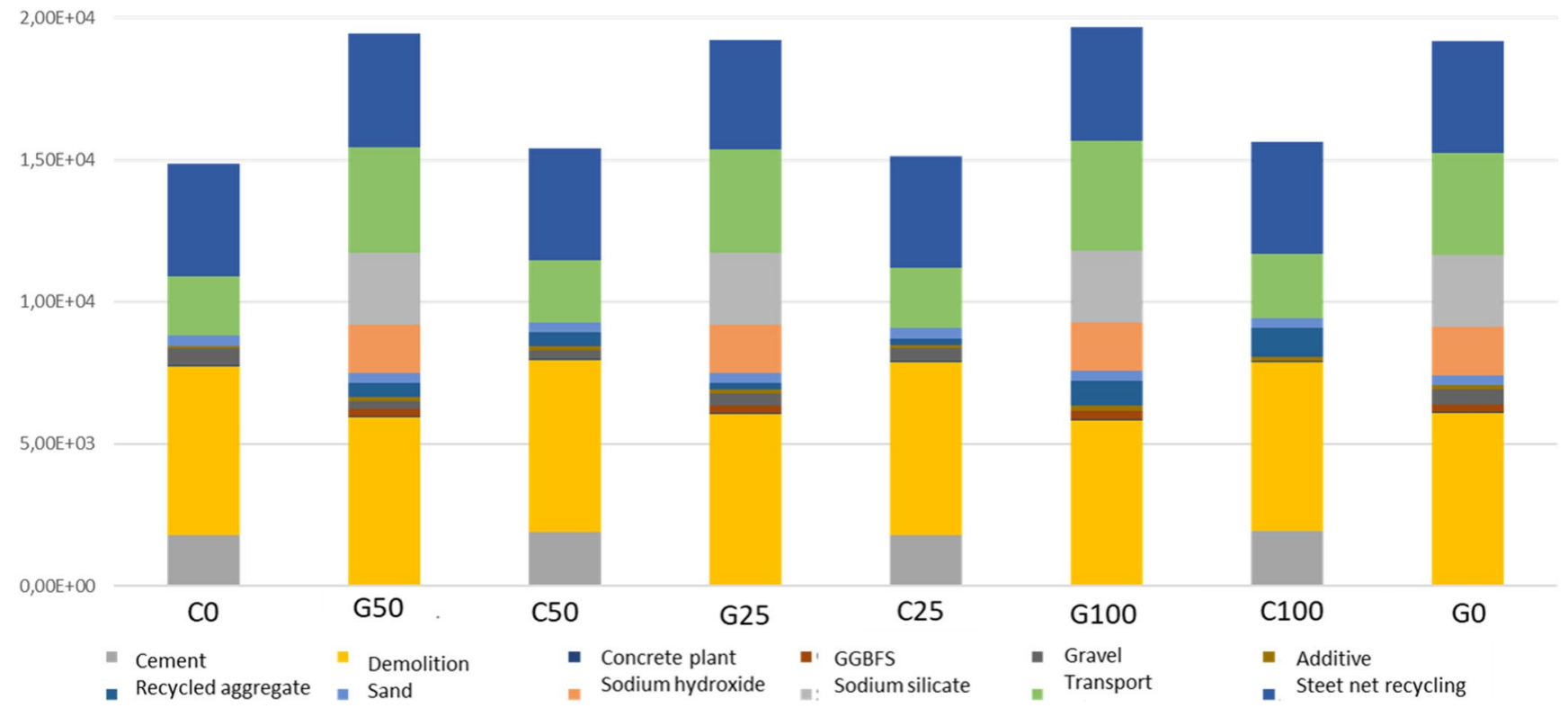

Fig. 10 Impact $2002+$, normalization stage for each process, terrestrial ecotoxicity 
Table 5 Summary of the main results and scientific questions

\begin{tabular}{|c|c|c|}
\hline Research question & Response & Future developments \\
\hline $\begin{array}{l}\text { Does the use of recycled } \\
\text { aggregates respect the principle } \\
\text { of an efficient circular } \\
\text { economy? }\end{array}$ & $\begin{array}{l}\text { Yes: The use of recycled aggregates is always preferable } \\
\text { compared to the traditional solution }(\mathrm{C} 0) \text {. } \\
\text { The zero waste scenario is accompanied by reduced } \\
\text { emissions. }\end{array}$ & $\begin{array}{l}\text { Analyse the impact deriving from the use of recycled } \\
\text { aggregates from a mobile plant in order to evaluate the } \\
\text { potential logistical advantage. }\end{array}$ \\
\hline $\begin{array}{l}\text { How much does steel net of } \\
\text { recycling affect? }\end{array}$ & $\begin{array}{l}\text { Net of recycling, steel accounts for around } 15 \% \text { of the } \\
\text { main categories of the IMPACT } 2002+\text { method. Other } \\
\text { categories, such as "mineral extraction" are mainly } \\
\text { influenced by the material constituting the } \\
\text { reinforcement. }\end{array}$ & $\begin{array}{l}\text { Analyse the variation of the eco-profile of the mixtures in } \\
\text { response to the reduction of the steel content in the } \\
\text { lower density solutions. }\end{array}$ \\
\hline $\begin{array}{l}\text { How do transport processes } \\
\text { impact? }\end{array}$ & $\begin{array}{l}\text { Transport is not particularly important for the main } \\
\text { impact categories of the IMPACT } 2002+\text { method. }\end{array}$ & $\begin{array}{l}\text { Changing method, adopting one that gives great } \\
\text { importance to categories such as "respiratory } \\
\text { organics" and "land occupation", could lead to a } \\
\text { strong dependence of the results on the hypotheses on } \\
\text { distances. }\end{array}$ \\
\hline $\begin{array}{l}\text { Geopolymer binder vs traditional } \\
\text { binder: which one is less } \\
\text { impactful? }\end{array}$ & $\begin{array}{l}\text { The advantage of using geopolymers is found in the } 20 \% \\
\text { reduction of the "global warming" phenomenon; on } \\
\text { the other hand, the use of geopolymers is not } \\
\text { recommended in the remaining categories. }\end{array}$ & $\begin{array}{l}\text { Analyse in detail the production process of sodium } \\
\text { hydroxide and sodium silicate in order to identify } \\
\text { critical issues. }\end{array}$ \\
\hline
\end{tabular}

the GGBFS binder and the traditional binder (Fig. 9); even by adapting the steel content to the density of the mixture, one could arrive at a favourable situation for the GGBFSbased concrete. At the moment, with the hypoth- eses made, the most environmentally sustainable mix for the non-carcinogens category is the one with traditional binder and $25 \%$ of recycled aggregates.

\subsubsection{Terrestrial ecotoxicity}

The phase that contributes the most to this category of impact is the demolition phase, along with transport and steel (Fig. 10). Therefore, once again, a better distribution of facilities, reducing the distances to be covered would reduce the impacts associated with transport. A lower density of the mixture, allowing a lower quantity of steel in the production of the reinforcement, would allow a reduction of the environmental load.

\section{Results and discussion}

It is interesting to see the impact results. However, it is well known that geopolymers are more impactful because of silicate and sodium hydroxide, though the study validates the application of circular economy concept into construction sector as suggested by the European Directive 2008/98/EC. Thus, the results seem to discourage the production of the concrete based on geopolymer cement mixtures. In fact, if on the one hand the use of geopolymers mitigates the global warming and on the other the high energy consumption (electricity and heat) makes it right now, their use is notrecommended.
The obtained results confirm the validity of the circular economy perspective in the construction sector, indicated by the European legislation. Thankfully, the challenges of sustainable construction, industrial growth and the importance of resource efficiency are now clearly recognised by governments around the world and are now at the forefront of strategy and policy. Furthermore, the results demonstrate that transportation is not found particularly important for main impact categories of IMPACT 2002+ method. Table 5 summarizes the main results of the study.

\section{Conclusion}

The problems related to the increase in C\&DW, together with the desire to reduce the environmental impacts deriving from the construction sector, have pushed this research. After a careful literature analysis aimed at identifying the best practices of the LCA applied to the construction sector, a comparative LCA of concrete with recycled aggregates was carried out. In this study, four different mix proportions of concrete mixtures with Portland cement and four different geopolymeric mixtures were examined. It was therefore possible to identify the best scenario to investigate, as well as to evaluate, the effective validity of the application of the circular economy concept in the construction sector suggested by the European Directive 2008/98/EC. With the assumptions made in the present study, the solution consisting in concrete with $25 \%$ of recycled aggregates is the best from the environmental point of view. However, all solutions with recycled aggregates are not more impacting than those having exclusively gravel in the mix design. Therefore, the recycling of concrete for the 
production of secondary raw materials is perfectly in line with the dictates of an efficient circular economy. Excluding the recycling, steel accounts for about $15 \%$ in two of the main categories of the IMPACT $2002+$ method and about $30 \%$ in the Respiratory Inorganics category. Transportation is not particularly important for the main impact categories of IMPACT $2002+$ method. As regards the possibility of using GGBFSbased concrete, these represent an already valid alternative regarding the reduction of global warming. However, the big impact in the other categories, connected to the production of sodium silicate and sodium hydroxide, represents an obstacle to their employment. The weak point of this study is represented by the absence of primary data: databases and data in literature have been used. The above perspectives indicate the importance of studying in detail the production process of precursors in order to identify the critical issues: a possible reduction of the environmental load connected to the production of sodium silicate and sodium hydroxide would increase the employment of third-generation cements. A possible future implementation of the present study is certainly to carry out an overall assessment and to determine the most costeffective option among the different competing alternatives through the life cycle cost analysis. Furthermore, it would be interesting to study in future research what would happen in case of production of recycled aggregates of enough quality in a mobile plant, followed by a re-use on site. It would be also interesting to examine an already developed context where the distances to travel are shorter. Finally, in the future research, a sensitivity analysis will be developed, since it is a significant tool for studying the robustness of results and their sensitivity to uncertainty factors in life cycle assessment (LCA). It highlights the most important set of model parameters to determine whether data quality needs to be improved and to enhance interpretation of results.

\section{References}

Akhtar A, Sarmah (2018) Construction and demolition waste generation and properties ofrecycled aggregate concrete: aglobalperspective.J Cleaner Prod 186:262-281

Bare JC, Hofstetter P, Penningtonne DW, Helias A, de Haes U (2000) Midpoints versus endpoints: the sacrifices and benefits. Int J Life Cycle Assess 5(6):319-326

Blengini GA, Garbarino E (2010) Resources and waste management in Turin (Italy): the role of recycled aggregates in the sustainable supply mix. J Clean Prod 18(10-11):1021-1030

Blengini GA, Garbarino E, Šolar S, Shields DJ, Hámor T, Vinai R, Agioutantis Z (2012) Life cycle assessment guidelines for the sustainable production and recycling of aggregates: the sustainable aggregates resource management project (SARMa). J Clean Prod 27: 177-181

Blengini GA, Garbarino E, Bevilacqua P (2017) Sustainability and integration between mineral resources and C\&DW management: overview of key issues towards a resource-efficient Europe. Env Eng Man J 16(2):493-502

Borghi G, Pantini S, Rigamonti L (2018) Life cycle assessment of nonhazardous construction and demolition waste (CDW) management in Lombardy region (Italy). J CleanProd 184:815-825

Braga AM, Silvestre JD, de Brito J (2017) Compared environmental and economic impact from cradle to gate of concrete with natural and recycled coarse aggregates. J Clean Prod 162:529-543

Chen C, Habert G, Bouzidi Y, Jullien A, Ventura A (2010) LCA allocation procedure used as an incitative method for waste recycling: an application to mineral additions in concrete. Res Con Rec 54(12): 1231-1240

Chen Z, Gu H, Bergman RD, Liang S (2020) Comparative life-cycle assessment of a high-rise mass timber building with an equivalent reinforced concrete alternative using the Athena impact estimator for buildings. Sustainability (Switzerland) 12(11):4708

Colangelo F, Cioffi R (2017) Mechanical properties and durability of mortar containing fine fraction of demolition wastes produced by selective demolition in South Italy. Comp Part B: Eng 115:43-50

ColangeloF, Petrillo A, Cioffi R, BorrelliC, Forcina A(2018a) Life cycle assessment of recycled concretes: a case study in southern Italy. Sci Total Env 615:1506-1517

Colangelo F, Forcina A, Farina I, Petrillo A (2018b) Life cycle assessment (LCA) of different kinds of concrete containing waste for sustainable construction. Buildings 8(5):70

Colangelo F, Navarro TG, Petrillo A, Farina I, Cioffi R (2020) Life-cycle impact of concrete with recycled materials. Encyclopedia of Renewable and Sustainable Materials, Volume 5(2020):414-421

COM (2012) 433, COMMUNICATION FROM THE COMMISSION TO THE EUROPEAN PARLIAMENT AND THE COUNCIL Strategy for the sustainable competitiveness of the construction sector and its enterprises, http://eur-lex.europa.eu/procedure/EN/ 201859, Brussels, 31.7.2012, COM(2012) 433 final

COM (2014) 445, COMMUNICATION FROM THE COMMISSION TO THE EUROPEAN PARLIAMENT AND THE COUNCIL, http://ec.europa.eu/e nvironment/euss d/pdf/ SustainableBuildingsCommunication.pdf, Brussels, 1.7.2014 $\operatorname{COM}(2014) 445$ final

Davidovits J (2018) Geopolymers based on natural and synthetic metakaolin a critical review. Ceramic Eng Science Proc 38(3): 201-214

Di Maria A, Eyckmans J, Van Acker K (2018) Downcycling versus recycling of construction and demolition waste: combining LCA and LCC to support sustainable policy making. Waste Man 75:3-21

Directive 2008/98/EC on waste (Waste Framework Directive), http://eurlex.europa.eu/legal-content/EN/TXT/?uri=CELEX:32008L0098

EN 1992-1-1:(2004) Eurocode 2: Design of concrete structures - Part 11: General rules and rules for buildings

Estanqueiro B, Dinis Silvestre J, de Brito J, Duarte Pinheiro M (2018) Environmental life cycle assessment of coarse natural and recycled aggregates for concrete. Eur J Env Civ Eng 22(4):429-449

Etxeberria M, Vázquez E, Marí A, Barra M (2007) Influence of amount of recycled coarse aggregates and production process on properties of recycled aggregate concrete. Cem Conc Res 37(5):735-742

EU construction \& demolition waste management protocol (2016) Brussels

Gálvez-Martos J-L, Styles D, Schoenberger H, Zeschmar-Lahl B (2018) Construction and demolition waste best management practice in Europe. Res Con Rec 136:166-178

Gluth, G.J.G., Arbi, K., Bernal, S.A., Bondar, D., Castel, A., Chithiraputhiran, S., Dehghan, A., Dombrowski-Daube, K., Dubey, A., Ducman, V., Peterson, K., Pipilikaki, P., Valcke, S.L.A., Ye, G., Hajimohammadi, A., van Deventer, J.S.J., 2017. Characterisation of one-part geopolymer binders made from fly ash. Waste Biom Val, 8(1), pp. 225-233 
Gomes R, Silvestre JD, de Brito J (2020) Environmental, economic and energy life cycle assessment "from cradle to cradle" (3E-C2C) of flat roofs. Journal of Building Engineering 32:101436

ISO 14040 (2006) Environmental management life cycle assessment. Principles and Framework. ISO, Geneva

ISO 14044 (2006) Environmental management. Life cycle assessment. Requirements and Guidelines. ISO, Geneva

Jafary Nasab T, Monavari SM, Jozi SA, Majedi H (2020) Assessment of carbon footprint in the construction phase of high-rise constructions in Tehran. Int J Environ Sci Technol 17(6):3153-3164

Jolliet O, Margni M, Charles R, Humbert S, Payet J, Rebitzer G, Rosenbaum R (2003) Impact 2002+: a new life cycle impact assessment methodology. Int J Life Cycle Assess 8(6):324-333

Khan MW, Ali Y, De Felice F, Salman A, Petrillo A (2019) Impact of brick kilns industry on environment and human health in Pakistan. Sci Total Environ 678:383-389

Knoeri C, Sanyé-Mengual E, Althaus H-J (2013) Comparative LCA of recycled and conventional concrete for structural applications. Int J Life Cycle Assess 18(5):909-918

$\mathrm{Lu} \mathrm{W}$, Yan H (2011) A framework for understanding waste management studies in construction. Waste Man 31:1252-1260

Marinković S, Radonjanin V, Malešev M, Ignjatović I (2010) Comparative environmental assessment of natural and recycled aggregate concrete. Waste Man 30(11):2255-2264

Mercante IT, Bovea MD, Ibáñez-Forés V, Arena AP (2012) Life cycle assessment of construction and demolition waste management systems: a Spanish case study. Int J Life Cycle Assess 17(2):232-241

Pantini S, Giurato M, Rigamonti L (2019) A LCA study to investigate resource-efficient strategies for managing post-consumer gypsum waste in Lombardy region (Italy). Res Con Rec 147:157-168

Petrillo A, Cioffi R, De Felice F, Colangelo F, Borrelli C (2016) An environmental evaluation: a comparison between geopolymer and OPC concrete paving blocks manufacturing process in Italy. Env Prog Sus Energy 35(6):1699-1708
Provis JL (2017) Alkali-activated cementitious materials and concretes steps towards standardization, American Concrete Inst, ACISpecial Publication 2017-January (SP 320), pp. 444-448

Sayagh S, Ventura A, Hoang T, François D (2010) Sensitivity of the LCA allocation procedure for BFS recycled into pavement structures. Res cons rec 54(6):348-358

Tangtinthai N, Heidrich O, Manning DAC (2019) Role of policy in managing mined resources for construction in Europe and emerging economies. J Env Man 236:613-621

Tošić N, Marinković S, Dašić T, Stanić M (2015) Multicriteria optimization of natural and recycled aggregate concrete for structural use. J Clean Prod 87(1):766-776

Van den Heede P, De BelieN (2012) Environmental impact and life cycle assessment (LCA) of traditional and 'green' concretes: literature review and theoretical calculations. Cem Conc Comp 34(4):431442

Vossberg C, Mason-Jones K, Cohen B (2014) An energetic life cycle assessment of C\&D waste and container glass recycling in Cape Town, South Africa. Res Con Rec 88:39-49

Walling SA, Notman S, Watts P, Govan N, Provis JL (2019) Portland cement based immobilization/destruction of chemical weapon agent degradation products. Industrial Eng Chemistry Res 58(24):1038310393

Wu H, Zuo J, Yuan H, Zillante G, Wang J (2019) A review of performance assessment methods for construction and demolition waste management. Res Cons Recycling 150:104407

Zhang C, Hu M, Dong L, Gebremariam A, Mirand-Xicotencatl B, Di Maio F, Tukker A (2019) Eco-efficiency assessment of technological innovations in high-grade concrete recycling. Res Cons Recycling 149:649-663

Publisher's note Springer Nature remains neutral with regard to jurisdictional claims in published maps and institutional affiliations. 